\title{
RELATION OF SERUM TRIGLYCERIDES IN CAUSING INSULIN RESISTANCE AMONG PATIENTS WITH CIRRHOSIS IN A TERTIARY CARE CENTER
}

\author{
Shaik Sulaiman Meeran ${ }^{1}$, Karthika², Ramesh ${ }^{3}$ \\ ${ }^{1}$ Assistant Professor, Department of General Medicine, Government Royapettah Hospital, Chennai. \\ 2Junior Resident, Department of General Medicine, Government Royapettah Hospital, Chennai. \\ 3Junior Resident, Department of General Medicine, Government Royapettah Hospital, Chennai.
}

\begin{abstract}
\section{BACKGROUND}

Cirrhosis of liver disturbs the functions of liver. There are many sources to tell that insulin resistance occurs in cirrhosi s, which precedes impaired glucose tolerance and frank diabetes. Also many studies conducted so far found that lipid profile alterations are common in them. The reasons of insulin resistance are proposed to be many.
\end{abstract}

\section{OBJECTIVE}

This study is done to find the relation of serum triglycerides in causing insulin resistance among patients with cirrhosis in a tertiary care center.

\section{MATERIALS AND METHODS}

The study was a cross-sectional study of 50 subjects done in Government Royapettah Hospital. Patients were selected according to the inclusion criteria. A detailed history was taken and a thorough clinical examination was done followed by further investigations, all of which were recorded in a pre-designed, structured proforma. Insulin resistance was assessed using three indices: HOMA1 IR, HOMA2 IR calculator and TyG index.

\section{RESULTS}

The mean age of the population was $46.18 \pm 9.78$ years; $94 \%$ of patients are males and $6 \%$ are females. Among the fifty subjects included 34\% had insulin resistance according to HOMA 1 IR (p 0.024) and 28\% with HOMA2 IR (p 0.002). Insulin resistance using both HOMA 1 and 2 was significantly increased in Child Turcotte Pugh $\mathrm{C}(\mathrm{p}<0.001$ for both). Insulin resistance was not demonstrated in any of the subjects using TyG index. Triglyceride levels are not elevated in our study population. There was positive correlation between insulin resistance and fasting glucose and insulin.

\section{CONCLUSION}

Insulin resistance is demonstrated in liver cirrhosis, which is increased with advancing disease and it has no relation with serum triglycerides. It can be concluded that regular monitoring of glycaemic status is mandatory in these patients, which would have definite bearing upon treatment strategy.

\section{KEYWORDS}

Cirrhosis, Insulin Resistance, Triglycerides, Homeostatic Model Assessment, Child Turcotte Pugh.

HOW TO CITE THIS ARTICLE: Meeran SS, Karthika, Ramesh. Relation of serum triglycerides in causing insulin resistance among patients with cirrhosis in a tertiary care center. J. Evolution Med. Dent. Sci. 2016;5(70):5123-5126, DOI: $10.14260 /$ jemds/2016/1162

\section{INTRODUCTION}

Liver, the largest gland in our body is the hub of various synthetic, metabolic and excretory functions. Cirrhosis disrupts the liver functions in every aspect. Bohan et al(1) who first described about occurrence of diabetes in cirrhosis found that $57 \%$ of them can develop insulin resistance, $14 \%$ go for diabetes and $60-80 \%$ develop impaired glucose tolerance. $(2,3)$ The occurrence of insulin resistance may have clinical implications, as it increases the complications like gastrointestinal haemorrhage and hepatocellular carcinoma.

Numerous studies done so far proposed various reasons like impaired clearance of insulin by liver due to hepatocellular

Financial or Other, Competing Interest: None.

Submission 25-07-2016, Peer Review 18-08-2016,

Acceptance 24-08-2016, Published 01-09-2016.

Corresponding Author:

Dr. Shaik Sulaiman Meeran,

Assistant Professor,

Department of General Medicine,

Government Royapettah Hospital, Chennai.

E-mail: sulaiman14@rediffmail.com

DOI: $10.14260 / \mathrm{jemds} / 2016 / 1162$ fibrosis or portosystemic shunting of insulin or impaired feedback regulation of insulin or increased pancreatic insulin secretion, but the exact mechanism is still unclear. Many studies concluded that insulin resistance could be due to insulin receptor and post receptor defects resulting in hyperinsulinaemia.(3)

Liver plays an important role in lipids and lipoprotein metabolism. There were many studies previously conducted in various parts of world found that dyslipidaemia is common in liver diseases like reduced cholesterol, HDL, LDL and TGL and suggested that cirrhosis is a state of hypolipidaemia.(4,5) Kackar et al found that the serum cholesterol levels decreases progressively with the progress of alcoholic cirrhosis.(6)

But there was an Indian study conducted in a NorthEastern Teaching Hospital showed elevated triglycerides and reduced LDL and total cholesterol occur in them. In this study, we have tried to find any relation of triglycerides with insulin resistance in cirrhosis. 


\section{MATERIALS AND METHODS}

This study was conducted in Government Royapettah Hospital for a duration of 1 year from July 2014 to July 2015. Patients were included in the study after getting informed consent. Ethical Committee Clearance was obtained from Kilpauk Medical College.

Study Design: It was designed as cross-sectional study.

\section{Study Population: 50.}

\section{Inclusion Criteria}

Patients with cirrhosis already proven by imaging who attends Medicine and Medical Gastroenterology Outpatient Clinic and inpatients in medical wards.

\section{Exclusion Criteria}

1. Diabetes mellitus as defined by ADA with fasting blood glucose $>126 \mathrm{mg} / \mathrm{dL}$.

2. Hepatitis $C$ virus infection.

3. Pregnancy.

4. Lactation.

5. Cardiac failure.

6. Renal failure.

7. Respiratory failure.

8. Hepatocellular carcinoma.

9. Presence of infection and acute decompensation in the prior 2 wks.

10. Prescription of hypolipidaemic drugs, antihypertensives, corticosteroid, bronchodilator, vasoactive or hypoglycaemic agents within 1 month.

\section{METHODOLOGY}

Patients who were already diagnosed to have cirrhosis and attending Medical or Medical Gastroenterology Outpatient Clinics and Inpatients in medical ward were taken into study. The sample size was set to be 50 . The procedures to be employed were explained to the patients and written consent was obtained from all patients included in the study. A detailed history was taken and a thorough clinical examination was done followed by further investigations, all of which were recorded in a pre-designed structured proforma. Height and weight were measured. Presence of ascites and pedal oedema were noted.

\author{
After getting Consent from the Patients following \\ Investigations were Done \\ 1. Fasting insulin. \\ 2. Fasting blood glucose. \\ 3. Blood urea, Serum creatinine. \\ 4. Serum triglycerides. \\ 5. Liver function tests - bilirubin, AST, ALT, ALP, serum total \\ protein, serum albumin. \\ 6. Prothrombin Time/International Normalised Ratio \\ (INR). \\ 7. Ultrasound abdomen.
}

Child Pugh Scores were calculated by adding the scores of the five factors (Serum bilirubin, serum albumin, prothrombin time, grade of ascites and hepatic encephalopathy) in order to classify patients according to severity of CLD into Child-Pugh class A (a score of 5-6), B (7-9) or C (10 or above). Body mass index was calculated using the formula weight $(\mathrm{kg}) /$ height* height $(\mathrm{m})$. If ascites was present, then correction of 4 was given for weight.

\section{Insulin Resistance \\ HOMA 1R(7)}

\{Fasting insulin (ц U/dl) * fasting glucose $(\mathrm{mmol} / \mathrm{L})\} / 22.5$.

A value $>2.7$ is taken as insulin resistance.

\section{HOMA 2R}

Programmed calculator downloaded from University of Oxford. http://www.dtu.ox.ac.uk/. Value of $>1.8$ is taken as insulin resistance.

\section{TyG Index ${ }^{(8)}$}

The formula is ln (fasting triglycerides $\mathrm{mg} / \mathrm{dL}$ ) ${ }^{*}$ fasting glucose $(\mathrm{mg} / \mathrm{dL}) / 2$ \}. The cut-off value is 4.6 .

\section{Results and Statistical Analysis}

The data obtained was analysed using SPSS software. Chi square test was used for comparison of dichotomous variables. A $p$ value of $<0.05$ was taken as statistically significant value. Pearson correlation coefficient was used to compare the regression coefficient between two groups.

\section{RESULTS}

The mean age of study population is $46.18 \pm 9.78$ years. The minimum age is 31 years and maximum one is 75 years with majority among 41-50 years' group. Out of fifty cases, 47 cases are male and only 3 are female.

In our study 17 patients out of 50 had insulin resistance by HOMA 1, which accounts for $34 \%$ of patients which is statistically significant with $p$ value $<0.001$. Out of 17 patients who had insulin resistance 3 patients $(17.6 \%)$ were in the age group of 30-40 years, 8 patients (47.1\%) were in 41-50 years, 4 patients $(23.5 \%)$ were in $51-60$ years and 2 patients $(11.8 \%)$ were in more than 60 years' age group. Out of 50 patients 14 patients $(28 \%)$ had insulin resistance according to HOMA 2 IR score ( $\mathrm{p}$ value of 0.002$)$. Out of 14 patients, 3 patients $(21.4 \%)$ were in age group 30-40 years, 8 patients (57.1\%) in $41-50$ years' group, 3 patients (21.4\%) in 51- 60 years' age group and no one were above 60 years' group.

In this study, 18 patients were in CTP A, 19 in B and 13 in CTP C score. By HOMA1- IR, among 18 CTP A patients 1 had insulin resistance, among 19 CTP B patients 4 had insulin resistance and among 13 CTP $\mathrm{C}$ patients 12 had insulin resistance. As the CTP grade increases insulin resistance among the patients increases, which was statistically significant ( $\mathrm{p}$ value $<0.001$ ).

Out of 18 patients in CTP A score, only 1 had insulin resistance according to HOMA 2-IR and out of 19 patients in CTP B score 1 had insulin resistance and out of 13 patients in CTP C score 12 had insulin resistance which was statistically very significant $p<0.001$. There is positive correlation between HOMA2 IR and BMI, fasting glucose and fasting insulin. There is no correlation between fasting triglyceride and insulin resistance by HOMA2 IR score.

In our study, out of 50 patients only two patients had fasting triglyceride values $>150 \mathrm{mg} / \mathrm{dL}$ with majority had values $<100 \mathrm{mg} / \mathrm{dL}$. All the 50 patients had TyG index $<4.68$ in our study. 
Baseline Descriptive Characteristics of the Study Group

\begin{tabular}{|c|c|c|c|c|c|}
\hline & $z$ & $\stackrel{\Xi}{\Xi}$ & 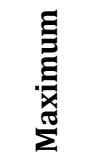 & 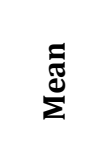 & 密 \\
\hline $\begin{array}{l}\text { Age in } \\
\text { Years }\end{array}$ & 50 & 30 & 75 & 46.18 & 9.78 \\
\hline BMI & 50 & 15.79 & 46.25 & 22.13 & 5.09 \\
\hline FBS & 50 & 60 & 126 & 100.10 & 27.77 \\
\hline $\begin{array}{c}\text { FBS } \\
\text { MMOL/L }\end{array}$ & 50 & 3.3 & 9.60 & 5.56 & 1.54 \\
\hline $\begin{array}{c}\text { Fasting } \\
\text { TGL }\end{array}$ & 50 & 56 & 172 & 89.36 & 26.30 \\
\hline $\begin{array}{c}\text { Fasting } \\
\text { Insulin } \\
\text { (Microgm/ } \\
\text { dL) }\end{array}$ & 50 & 3.00 & 58.09 & 12.41 & 11.60 \\
\hline HOMA 1R & 50 & .50 & 16.78 & 3.27 & 3.50 \\
\hline HOMA 2 & 50 & .4 & 7.3 & 1.53 & 1.28 \\
\hline TyG Index & 50 & 3.3 & 4.0 & 3.61 & .172 \\
\hline $\begin{array}{c}\text { Valid N } \\
\text { (List Wise) }\end{array}$ & 50 & & & & \\
\hline
\end{tabular}

HOMA-1

\begin{tabular}{|c|c|c|c|}
\hline & Frequency & Percent & P value \\
\hline IR - & 33 & 66.0 & \multirow{2}{*}{0.024} \\
\hline IR + & 17 & 34.0 & \\
\hline Total & $\mathbf{5 0}$ & $\mathbf{1 0 0 . 0}$ & \\
\hline
\end{tabular}

This table shows number and percentage of our study group showing insulin resistance according to HOMA1 IR and statistical significance.

\begin{tabular}{|c|c|c|c|}
\hline & Frequency & Percent & \\
\cline { 1 - 3 } IR - & 36 & 72.0 & \multirow{2}{*}{ P value 0.002} \\
\cline { 1 - 2 }+ & 14 & 28.0 & \\
\hline Total & $\mathbf{5 0}$ & $\mathbf{1 0 0 . 0}$ & \\
\hline
\end{tabular}

This table shows number and percentage of our study group showing insulin resistance according to HOMA2-IR score.

\section{Correlation with HOMA1-1R}

\begin{tabular}{|c|c|c|c|}
\hline & & $\begin{array}{c}\text { Pearson } \\
\text { Cooefficient }\end{array}$ & P value \\
\hline BMI & HOMA1-IR & 0.422 & 0.002 \\
\hline FBS & HOMA1-IR & 0.461 & 0.001 \\
\hline Fasting TGL & HOMA1-IR & -0.144 & 0.320 \\
\hline $\begin{array}{c}\text { Fasting } \\
\text { Insulin } \\
(\text { Microgm/dL) }\end{array}$ & HOMA1-IR & 0.968 & $<0.001$ \\
\hline
\end{tabular}

\section{Correlation with HOMA2-IR}

\begin{tabular}{|c|c|c|c|}
\hline & & $\begin{array}{c}\text { Pearson } \\
\text { Coefficient }\end{array}$ & $\begin{array}{c}\text { P } \\
\text { value }\end{array}$ \\
\hline BMI & HOMA 2 & 0.422 & 0.002 \\
\hline FBS & HOMA 2 & 0.351 & 0.013 \\
\hline Fasting TGL & HOMA 2 & -0.101 & 0.485 \\
\hline $\begin{array}{c}\text { Fasting Insulin } \\
\text { (Microgram/dL) }\end{array}$ & HOMA 2 & 0.935 & $<0.001$ \\
\hline
\end{tabular}

\section{DISCUSSION}

Diabetes in the context of cirrhosis termed as hepatogenous diabetes has little micro and vascular implications, instead it may cost upon the treatment of cirrhosis. This study throws light on the relation of triglycerides and insulin resistance among patients with cirrhosis.

The mean age of our study population is 46.18 years and majority are in the age group of 41-50 years. According to study conducted by Mukherjee et al from Calcutta National Medical College, the mean age of cirrhotic population was $44 \pm 10.2$ years. ${ }^{(9)}$ According to Douds et al, the mean age of alcoholic cirrhosis in South Asian male was 44 years.(10)

The male:female ratio of our study group is 15:1. In a study by Bhargava et al, the male:female ratio was found as $6: 1$. Another study by Sarkar et al also showed that $86 \%$ of cases of cirrhosis were males and $14 \%$ were females. The male preponderance of cirrhosis in South India is due to its aetiology of alcohol, which is more common in males. In our study, majority of patients are in CTP B (38\%) followed by CTP A (36\%).

We assessed insulin resistance using three scores and reference values are taken according to Bruno Geloneze et al, where the cut-off value using HOMA-1 was $>2.7$ and using HOMA-2 IR it was > 1.8.(7) Insulin resistance by HOMA-1 IR was present in $34 \%$ of patients, which was statistically significant ( $\mathrm{p}$ value $<0.05$ ). The common age group showing insulin resistance by HOMA1-IR in our study was $41-50$ years (36\%) followed by 30-40 years (32\%). Insulin resistance was found to be $28 \%$ of patients according to HOMA-2 IR with a p value 0.002 . The common age group showing insulin resistance by HOMA-2 in our study was $41-50$ years (36\%) followed by 30 40 years $(32 \%)$.

There was a study conducted by Goswami et al from Jodhpur, India, showed insulin resistance in $68.5 \%$ of euglycaemic cirrhotics and universally in all cirrhotics with recent diabetes. A study conducted in Spain by Eva Erice et al on insulin resistance in patients with cirrhosis and portal hypertension showed that insulin resistance by HOMA-2 IR was present in $60 \%$ of the study population.

Insulin resistance was found mostly in CTP C patients by both HOMA1-IR and HOMA2-IR, which contributed to about $92 \%$ and $92.3 \%$ of cases with HOMA1-IR and HOMA2-IR respectively. This is consistent with study from Jodhpur, India by Goswami and Bargava et al, where they showed significant increase in insulin resistance in patients with CTP $>10$ and MELD $>15$. However, another Indian study by Mukherjee et al from Calcutta showed no correlation with CTP score or with duration of illness.

As liver is the hub of major lipid synthesis and metabolism, derangements in lipid profile can be expected in liver cirrhosis. According to Jyotiprakash et al study from North-Eastern India, they concluded that serum total cholesterol values are lowered in alcoholic cirrhotic patients compared with the normal, healthy individuals. The serum HDL cholesterol and LDL cholesterol levels are also significantly decreased compared with the normal controls, but serum triglycerides were significantly increased in cases than controls. Kackar et al found that the serum cholesterol levels decreases progressively with the progress of alcoholic cirrhosis.(6)

In a Nigerian study, the median total cholesterol and HDL cholesterol levels were significantly higher in controls compared with cirrhotic patients; however, LDL cholesterol 
levels were higher in controls compared with cirrhotic patients and the difference was not statistically significant. However, alcoholic cirrhosis may be associated with increased total cholesterol and LDL cholesterol levels as found by Varghese et al(11) Another Indian study showed elevated triglycerides with decreased serum cholesterol in cirrhosis.(12)

Fernando et al from Mexico showed that TyG index and HOMA were almost similar in assessing IR. But in our study, we found that serum triglycerides were not elevated and so TyG index which is calculated based on triglycerides and fasting glucose failed to detect IR in those who are detected by HOMA model.

\section{CONCLUSION}

- $\quad$ The majority of patients with cirrhosis in our study are in the age group of 41-50 years.

- $\quad$ About $94 \%$ of patients included are males.

- Majority of population included are in CTP B followed by CTP C.

- Insulin resistance is found in $34 \%$ of patients using HOMA1-IR and $28 \%$ of patients using HOMA2-IR.

- TyG index failed to show insulin resistance in those shown by HOMA model.

- $\quad$ Serum triglyceride levels are not elevated in our study population.

- Insulin resistance is significantly higher in patients with CTP C by both HOMA-1 and HOMA- 2 .

- Insulin resistance demonstrated in these euglycaemic cirrhotics has no correlation with serum triglyceride levels.

So occurrence of impaired glucose tolerance and diabetes is a major concern in these patients, which could definitely alter the course of disease by increasing the complications. Hence, these patients may need regular glycaemic monitoring. Finally to conclude, cirrhosis of liver is an insulin resistant state and insulin resistance in these euglycaemic cirrhotics is not related to serum triglyceride levels, though altered lipid profile is expected.

\section{LIMITATIONS OF THE STUDY}

- The sample size is considerably very small.

- Duration of cirrhosis and different aetiologies are not considered.

- Relationship with sex and insulin resistance could not be assessed due to small number of female patients included in our study.

- Vitamin D levels were not assessed as decrease in their levels increase insulin resistance in cirrhosis.
- For some patients previous records could not be obtained about glycaemic status.

- Further follow-up of patients were not done, hence further assessment of glycaemic status could not be done.

\section{REFERENCES}

1. Bohan EM. Diabetes mellitus and cirrhosis of the liver: a case report. Del Med J 1947;19(11):212-15.

2. Megyesi C, Samols E, Marks V. Glucose tolerance and diabetes in chronic liver disease. Lancet 1967; 2(7525): 1051-6.

3. Perseghin G, Mazzaferro V, Sereni LP, et al. Contribution of reduced insulin sensitivity and secretion to the pathogenesis of hepatogenous diabetes: effect of liver transplantation. Hepatology 2000;31(3):694-703.

4. Ghadir MR, Riahin AA, Havaspour A, et al. The relationship between lipid profile and severity of liver damage in cirrhotic patients. Hepat Mon 2010;10(4):285-8.

5. Kroon PA, Powell EE. Liver, lipoproteins and disease: I. Biochemistry of lipoprotein metabolism. J Gastroenterol Hepatol 1992;7(2):214-24.

6. Kackar RR, Desai HG. Serum cholesterol in cirrhosis of liver. J Assoc Physicians India 2004;52:1007.

7. Geloneze B, Vasques AC, Stabe CF, et al. Homa1-ir and Homa2-ir indexes in identifying insulin resistance and metabolic syndrome. Brazilian metabolic syndrome study (BRAMS). Arq Bras Endocrinol Metab 2009;53(2):281-7.

8. Guerrero-Romero F, Simental-Mendia LE, Gonzalez-Ortiz $\mathrm{M}$, et al. The product of triglycerides and glucose, a simple measure of insulin sensitivity. Comparison with the euglycemic-hyperinsulinemic clamp. J Clin Endocrinol Metab 2010;95(7):3347-51.

9. Mukherjee S, Sarkar BS, Das KK, et al. A cross sectional study on occurrence of type 2 diabetes among patients admitted with chronic liver diseases in a medical college in Kolkata. International Journal of Medicine and Public Health 2013;3(1):44-7.

10. Douds AC, Cox MA, Iqbal TH, et al. Ethnic differences in cirrhosis of the liver in a british city: alcoholic cirrhosis in south Asian men. Alcohol Alcohol 2003;38(2):148-50.

11. Varghese JS, Krishnaprasad K, Upadhuyay R, et al. Lipoprotein profile in cirrhosis of liver. Eur J Gastroenterol Hepatol 2007;19(6):521-2.

12. Singh B, Gupta AK, Vishwakarma PK, et al. Study of blood sugar profile and lipid profile in cases of cirrhosis of liver. J Med Sci Research 2011;2(1):34-9. 